\title{
Rapid-deployment aortic valves: Do the data support a tipping point?
}

\author{
Jason P. Glotzbach, MD, and Stephen H. McKellar, MD, MSc
}

\footnotetext{
From the Division of Cardiothoracic Surgery, Department of Surgery, University of Utah School of Medicine, Salt Lake City, Utah.

Disclosures: Authors have nothing to disclose with regard to commercial support.

Received for publication July 7, 2017; accepted for publication July 14, 2017; available ahead of print Aug 18, 2017.

Address for reprints: Stephen H. McKellar, MD, MSc, Department of Cardiothoracic Surgery, University of Utah, 30 North 1900 East, SOM 3C-127, Salt Lake City, UT 84132 (E-mail: stephen.mckellar@hsc.utah.edu).

J Thorac Cardiovasc Surg 2017;154:1532-3

$0022-5223 / \$ 36.00$

Copyright (c) 2017 by The American Association for Thoracic Surgery

http://dx.doi.org/10.1016/j.jtcvs.2017.07.029
}

The tipping point is that magical moment when an idea, trend, or social behavior crosses a threshold, tips and spreads like wildfire.

\section{-Malcom Gladwell, The Tipping Point}

Laufler and colleagues ${ }^{2}$ are to be congratulated on their article entitled "Rapid-Deployment Valves: Finally the Fog Is Lifting_Benefits Beyond Crossclamp And Bypass Times," which appears in the current issue of the Journal. ${ }^{2}$ In this review article, they go beyond the well-known results of shorter crossclamp and bypass times to provide more clinically relevant outcomes than shorter intraoperative times. They review available hemodynamic, patientprosthesis mismatch, prosthetic valve endocarditis, and valve thrombosis data. They also provide a review of some of the potential downsides of rapid-deployment valves, such as costs and rate of permanent pacemakers. They review surgical aortic valve replacement (SAVR), transcatheter aortic valve replacement (TAVR), rapiddeployment SAVR, and sutureless SAVR.

When reviewing the data, ${ }^{2-4}$ they observed superior hemodynamic data, as assessed by postoperative echocardiography as measured in a core laboratory. They observed decreased mean valve gradients with equivalent effective orifice areas for the rapid-deployment SAVR valves. Similar decreases in the rate of patient-prosthesis mismatch with rapid-deployment SAVR, in both normalsized and small roots, was observed and the rates may even be superior to traditional SAVR. Reassuringly, the rate of prosthetic valve endocarditis does not appear to be increased, despite increased implantable material on the rapid-deployment SAVR valve, which is part of the covered stent. Although not rigorously studied, the risk of valve thrombosis in rapid-deployment SAVR valves does not appear to be as high as with TAVR.

That's the good news. Laufler and colleagues ${ }^{2}$ also responsibly review the potential downsides of the rapiddeployment SAVR technology: cost and the risk of needing a permanent pacemaker. They cite higher implant costs with clinical practice.

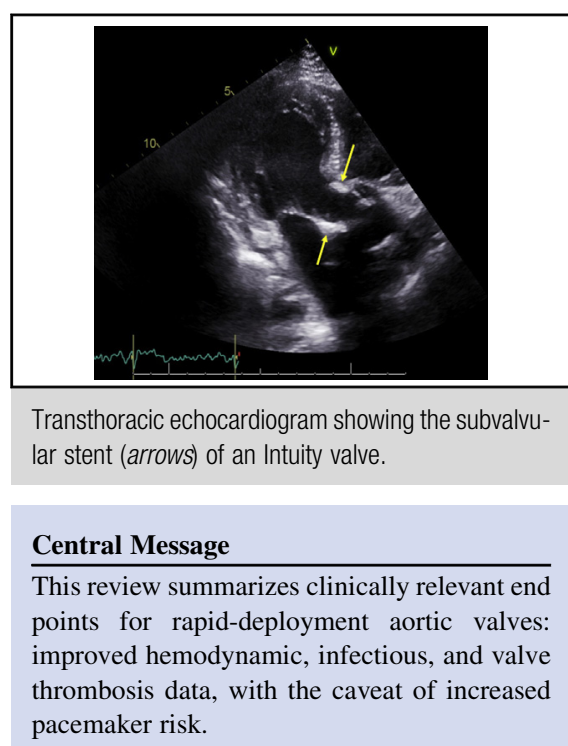

See Article page 1527.

equal or, in some cases superior, outcomes. When reviewing the data on pacemakers, it is clear that TAVR carries the highest risk $(\sim 20 \%$, although likely lower with newer TAVR valves), rapid-deployment SAVR carries an intermediate risk (7\%-14\%), and traditional SAVR carries the lowest risk (3\%) in isolated cases. The risks more than double for rapid-deployment SAVR and traditional SAVR as part of combined procedures.

In summary, the article of Laufler and colleagues ${ }^{2}$ provides more clinically relevant hemodynamic, infectious, and thrombosis data while acknowledging the increased risk of permanent pacemaker. Arguably, mean valve gradients and the need for a permanent pacemaker are more meaningful to patients than crossclamp and cardiopulmonary bypass times, but what is most important to patients is prosthesis durability. On this metric, only time and long-term studies will provide data about whether TAVR, SAVR, or rapid-deployment SAVR produces a more durable result. Taken together, these data are unlikely to provide sufficient evidence to support a "tipping point" from one type of aortic valve replacement to another. They do, however, bring up the question of whether new aortic valve replacement technologies (such as low-risk TAVR trials) should be compared with SAVR or with rapid-deployment SAVR. Eventually, when the durability question is answered, the field will see a tipping point that will change 


\section{References}

1. Gladwell M. The tipping point: how little things can make a big difference. Little, Brown, and Company; 2000.

2. Laufler G, Wiedemann D, Chitwood WR. Rapid-deployment valves: finally the fog is lifting - benefits beyond crossclamp and bypass times. J Thorac Cardiovasc Surg. 2017; 154:1527-31.

3. Kocher AA, Laufler G, Haverich A, Shrestha M, Walther T, Misfeld M, et al. Oneyear outcomes of the Surgical Treatment of Aortic Stenosis With a Next Genera-

tion Surgical Aortic Valve (TRITON) trial: a prospective multicenter study of rapid-deployment aortic valve replacement with the EDWARDS INTUITY Valve System. J Thorac Cardiovasc Surg. 2013;145:110-5; discussion 115-6.

4. Barnhart GR, Accola KD, Grossi EA, Woo YJ, Mubashir MA, Sabik JF, et al; TRANSFORM Trial Investigators. TRANSFORM (Multicenter Experience with Rapid Deployment Edwards INTUITY Valve System for Aortic Valve Replacement) US clinical trial: performance of a rapid deployment aortic device. J Thorac Cardiovasc Surg. 2017;153:241-51.e2. 